\title{
Dissolved Oxygen as a Measure for De- and Reaeration of Aqueous Media for Dissolution Testing
}

Steffen M. Diebold and Jennifer B. Dressman

Institut fuir Pharmazeutische Tecbnologie, 7. W. Goethe-Universitat Frankfurt, Germany

\section{Abstract}

In order to obtain reliable and reproducible results from dissolution tests, it is often necessary to deaerate the dissolution medium. In the current work, four different methods of degassing the medium were compared by measuring the concentration of oxygen in the medium before and after the deaeration procedure. The oxygen concentration was determined under defined conditions by using an oxygen sensor based on a Clark electrode. The method described in the USP 23 (beating to $45^{\circ} \mathrm{C}$ plus filtration) achieved an $85 \% \pm 11 \%$ reduction in the oxygen concentration. Heating to $100^{\circ} \mathrm{C}$ resulted in a reduction of only $50 \% \pm 3 \%$, while filtration reduced the oxygen content by $65 \% \pm 4 \%$. A method developed in our laboratory combining ultrasound and application of a vacuum achieved a $95 \% \pm 2 \%$ reduction. After degassing, the medium must usually be transferred to the ed that even careful filling resulted in a $37 \%$ increase in the oxygen content, while typical filling procedures resulted in an almost three-fold increase. It was further shown that the medium gradually becomes re-saturated during the dissolution test itself, at a rate that is dependent on the apparatus (basket versus paddle) and the rotational speed. 120 minutes into the test, the oxygen concentration was already $60 \%$ of the saturation value. Conclusions: The measurement of oxygen was demonstrated to be a reproducible and direct method for measuring the efficiency of deaeration. It was further shown that the efficiency of deaeration is highly dependent on the method used, and that re-introduction of air into the medium occurs not only during filling of the dissolution vessels but also during the dissolution test.

\section{Introduction}

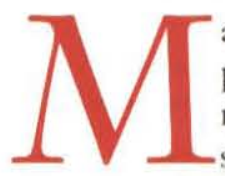

any authors emphasize the importance of deaeration of the media when performing dissolution tests for solid oral dosage forms. Calibrator tablets are commonly used to investigate whether or not the deaeration procedure was successful (1). A potential drawback of calibrator tablets is that they exhibit differences in hardness, particle size distribution of the active ingredient and the excipients that are inherent from the manufacturing process etc.. Therefore it would be useful to compare deaeration methods by a method that is independent of the manufacturing process.

As oxygen is ubiquitous, exhibits a constant partial pressure at a given altitude, and is easy to quantify with sensitive electrodes, it can be used to represent the content of air dissolved in liquids.
Furthermore, since oxygen possesses a low, virtually $\mathrm{pH}$-independent solubility in water (2), its dissolution rate is not subject to fluctuations in the $\mathrm{pH}$ of the medium. The objectives of the present work were to compare various deaeration methods and to investigate the rate of reaeration of the medium during the dissolution test itself, using oxygen as the test solute.

\section{Experimental}

2.1 Deaeration of dissolution media

Purified water was deaerated according to four different methods.

\subsection{1. "USP method"}

The medium was heated to $45^{\circ} \mathrm{C}$, filtered through $0.45 \mu \mathrm{m}$ membrane filters (diameter 50 $\mathrm{mm} /$ Schleicher \& Schüll, Dassel, Germany) under vacuum and stirred for about 5 minutes(3).

\subsubsection{Filtering at Room Temper- ature $\left(21^{\circ} \mathrm{C}\right)$ :}

To evaluate the efficiency of the filtration step separately, the medium was filtered at $21^{\circ} \mathrm{C}$ using the filters identical to those above.

\subsubsection{Heating $\left(45^{\circ} \mathrm{C} / 100^{\circ} \mathrm{C}\right)$ :}

To evaluate the efficiency of the heating step separately, $2 \mathrm{~L}$ of medium were heated for $3 \mathrm{~min}$. with vigorous stirring to $45^{\circ} \mathrm{C}$ and $100^{\circ} \mathrm{C}$, respectively. Then the medium was cooled immediately with the aid of an ice-bath to $37^{\circ} \mathrm{C}$.

\subsection{4. "Ultrasound/Vacuum method:"}

The dissolution medium was preheated to $37^{\circ} \mathrm{C}$ and transferred to a $2 \mathrm{~L}$ flask. The flask was placed in a sonicator bath (Transonic Digital 790/H,

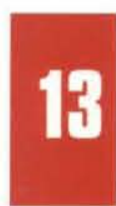




\section{Dissolved Oxygen.....entinued}

Elma, Singen) and the medium was deaerated using a combination of ultrasound and vacuum (approx. $80 \mathrm{mbar}$, produced by a membrane vacuum pump (MZ2C Synchro, Vacuubrand, Wertheim)). In an additional experiment, the procedure was repeated, with the exception of the temperature, which in this case was held at $21^{\circ} \mathrm{C}$. All experiments were performed in triplicate.

\subsection{Reaeration during dissolution test procedure}

The rate of reaeration of the medium during the dissolution test was determined in $900 \mathrm{~mL}$ medium (water deaerated according to method 2.1.4.) using Type 1 and 2 apparatus (DT6, Erweka, Heusenstamm, Germany) according to the USP 23 . The rotational speed was set at $50 \mathrm{rpm}$ and $100 \mathrm{rpm}$ for the paddle and for the basket experiments, since these speeds are frequently cited in current pharmacopeia (4). Additionally, the rate of reaeration due to diffusion only was assessed in stagnant media (0 rpm).

\subsection{Reaeration during filling procedures}

To evaluate the possibility that partial reaeration of the media occurs during manual filling of the media into the dissolution beakers we performed the following test:

The dissolution vessels were carefully filled with both vessels held at an angle so that the medium could be transferred slowly and carefully, without inducing any turbulence (method B 1 and 2).

In a further set of experiments we tried to mimic the "typical filling procedure"; the dissolution vessel was held vertical and filled from 5 $-10 \mathrm{~cm}$ above, without any special care (method N1 and 2)

\subsection{Determination of the concentra- tion of oxygen}

The oxygen concentration was measured directly using a CLARK (4)

electrode(Oxi 323 A, WTW, Weilheim, Germany) with an oxygen sensitive sensor (WTW CellOx 325). The sensor is calibrated by a two point procedure. The signal at zero current corresponds to less than $0.1 \%$ of the saturation value, while at maximum current the signal corresponds to the partial pressure of oxygen in the atmosphere. The reproducibility of the individual determinations was better than \pm 0.02 $\mathrm{mg} / \mathrm{L}$. The electrode itself consumes $11.4 \mu \mathrm{g} / \mathrm{h}$ of the available oxygen. This amount is negligible compared to the reported concentrations in the media. When determining the content of oxygen, the sensor always was located $7 \mathrm{~cm}$ underneath the liquid surface to account for the concentration gradient, and the temperature was maintained within \pm

\section{Aufbaud des Sauerstoffsensors CellOx 325} Construction of the oxygen sensor CellOx 325
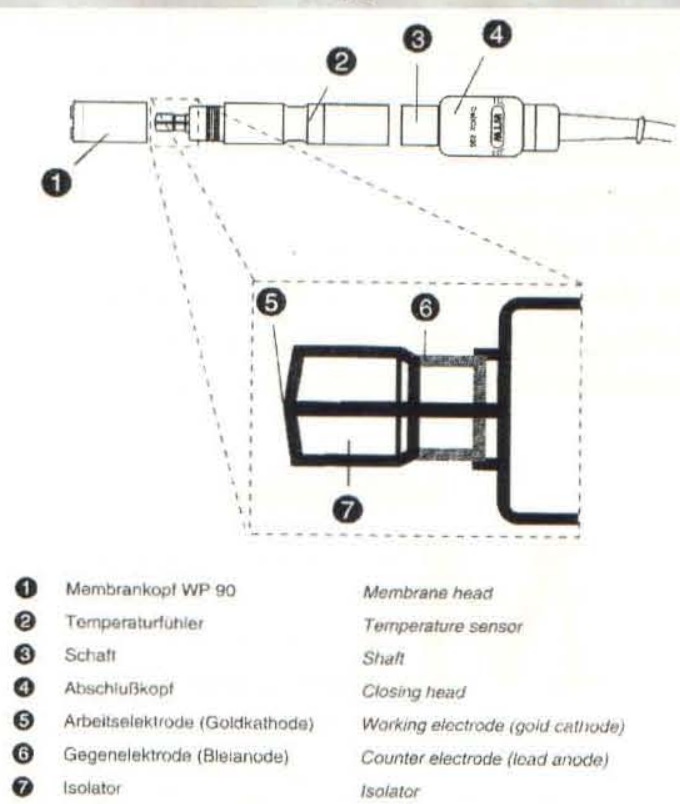

$$
\begin{aligned}
& \text { Membrane head } \\
& \text { Temperature sensor } \\
& \text { Shath } \\
& \text { Closing head } \\
& \text { Working electrode (goid cathode) } \\
& \text { Counter electrode (lead anode) } \\
& \text { Isolator }
\end{aligned}
$$

Figure 1 Construction of the oxygen sensor used for the described experiments. Figure taken from "WTW Oxy 323/325 instruction manual" (WTW, Weilheim, Germany)

$1^{\circ} \mathrm{C}$ of the desired value. Figure 1 demonstrates how the sensor works: The gold cathode reduces dissolved oxygen to solvated hydroxide ions while the lead anode is oxidated. The resulting current depends on the partial pressure and therefore the corresponding concentration of oxygen in the dissolution medium.

\section{Results and Diseussion}

\subsection{Deaeration}

Table 1 summarizes the results for the deaeration procedures. Merely heating to $45^{\circ} \mathrm{C}$ result- sible to achieve a final concentration of oxygen of about $1 \mathrm{mg} / \mathrm{L}$. Nevertheless, the most efficient method was the combination of ultrasound and vacuum (UVM). With this method, the starting content of oxygen was reduced by almost $95 \%$ with a standard deviation of less than $4 \%$ and $2 \%$ at $21^{\circ} \mathrm{C}$ and $37^{\circ} \mathrm{C}$, respectively.

\subsection{Reaeration}

Table 2 reports the rate of reaeration during frequently used dissolution tests. 120 minutes into the test the media are almost com- 
Table 1. Decrease in content of oxygen in the medium after applying different deaeration techniques

\begin{tabular}{|c|c|c|c|c|c|}
\hline method & $\begin{array}{l}\text { samples } \\
\text { (n) }\end{array}$ & $\begin{array}{c}\text { temperature } \\
\left({ }^{\circ} \mathrm{C}\right)\end{array}$ & $\begin{array}{l}\text { oxygenconc. }\left(21^{\circ} \mathrm{C}\right) \\
\text { before deaeration } \\
(\mathrm{mg} / \mathrm{L} \pm \mathrm{sd})\end{array}$ & $\begin{array}{l}\text { decrease of oxygenconc. } \\
\text { after deaeration } \\
(\mathrm{mg} / \mathrm{L} \pm \mathrm{sd})\end{array}$ & $(\% \pm s d)$ \\
\hline USPM & 9 & 43 & $7,3 \pm 0,8$ & $6,2 \pm 0,7$ & $84,9 \pm 11,3$ \\
\hline $\mathrm{F}$ & 3 & 21 & $8,4 \pm 0,3$ & $5,5 \pm 0,2$ & $65,5 \pm 3,6$ \\
\hline E 45 & 3 & 43 & $7,0 \pm 0,1$ & $0,7 \pm 0,1$ & $10,0 \pm 14,3$ \\
\hline E 100 & 3 & 43 & $7,0 \pm 0,1$ & $3,4 \pm 0,1$ & $48,6 \pm 2,9$ \\
\hline UVM 37 & 8 & 37 & $7,4 \pm 0,2$ & $7,0 \pm 0,1$ & $94,6 \pm 1,4$ \\
\hline UVM 21 & 3 & 21 & $9,0 \pm 0,2$ & $8,4 \pm 0,3$ & $93,3 \pm 3,6$ \\
\hline \multicolumn{6}{|c|}{ Legend } \\
\hline & $\begin{array}{l}\text { USPN } \\
\text { F } \\
\text { E45/E1 } \\
\text { UVM3 }\end{array}$ & 00 & \multicolumn{3}{|c|}{$\begin{array}{l}\text { Heating to } 45^{\circ} \mathrm{C}( \pm \mathrm{C}) \text { and } 100^{\circ} \mathrm{C}\left( \pm 1^{\circ} \mathrm{C}\right) \text {, respectively } \\
\text { "Ultrasound Vacuum Method" at } 37^{\circ} \mathrm{C}\left( \pm 1^{\circ} \mathrm{C}\right) \text { and } 21^{\circ} \mathrm{C}\left( \pm 1^{\circ} \mathrm{C}\right) \text {, } \\
\text { respectively }\end{array}$} \\
\hline
\end{tabular}

Table 2. Resaturation of the medium with oxygen during dissolution tests.

\begin{tabular}{|ccccccc|}
\hline $\begin{array}{c}\text { time } \\
\text { (min.) }\end{array}$ & $\begin{array}{c}0 \mathrm{rpm}(\mathrm{n}=1) \\
\text { content } \\
(\mathrm{mg} / \mathrm{L})\end{array}$ & $\begin{array}{c}\text { increase } \\
(\%)\end{array}$ & $\begin{array}{c}50 \mathrm{rpm} \text { paddle }(\mathrm{n}=3) \\
\text { content } \\
(\mathrm{mg} / \mathrm{L})\end{array}$ & $\begin{array}{c}100 \mathrm{rpm} \text { basket }(\mathrm{n}=1) \\
\text { increase } \\
(\%)\end{array}$ & $\begin{array}{c}\text { content } \\
(\mathrm{mg} / \mathrm{L})\end{array}$ & $\begin{array}{c}\text { increase } \\
(\%)\end{array}$ \\
\hline 0 & 2.3 & - & 1.4 & - & 2.2 & - \\
30 & 2.8 & 21.7 & 2.5 & 72.2 & 2.8 & 27.4 \\
60 & 3.1 & 10.7 & 3.2 & 30.6 & 3.4 & 18.3 \\
90 & 3.5 & 12.9 & 3.9 & 19.1 & 3.8 & 13.1 \\
120 & 3.8 & 8.6 & 4.3 & 12.2 & 4.2 & 9.7 \\
\hline
\end{tabular}

Dissolution of oxygen at $100 \mathrm{rpm}$ paddle versus basket

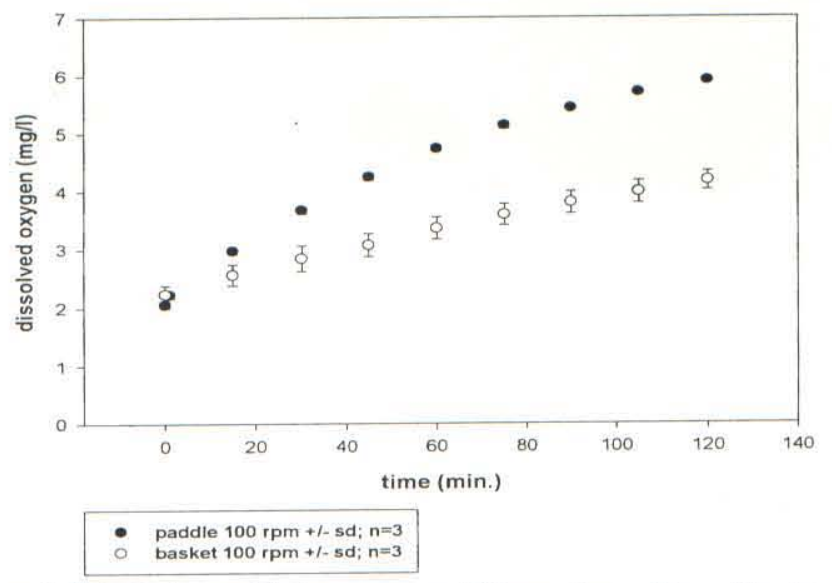

Figure 2. Dissolution profile for oxygen at $100 \mathrm{rpm}$ for paddle and basket. Experiments performed in triplicate.

Table 3. Increase in the oxygen content for different filling procedures.

\begin{tabular}{|ccccccc|}
\hline method & samples & $\begin{array}{c}\text { temperature } \\
\text { at measuring } \\
\left({ }^{\circ} \mathrm{C}\right)\end{array}$ & $\begin{array}{c}\text { oxygenconc. } \\
\text { before filling } \\
(\mathrm{mg} / \mathrm{L} \pm \mathrm{sd})\end{array}$ & $\begin{array}{c}\text { at } \\
\left({ }^{\circ} \mathrm{C}\right)\end{array}$ & $\begin{array}{c}\text { oxygenconc. } \\
\text { increase rate } \\
(\mathrm{mg} / \mathrm{L} \pm \mathrm{sd})\end{array}$ & $(\%)$ \\
\hline $\mathrm{B} 1$ & 15 & 37 & $1.1 \pm 0.4$ & 21 & $0.4 \pm 0.1$ & $36.4 \pm 25.0$ \\
$\mathrm{~B} 2$ & 3 & 37 & $0.6 \pm 0.1$ & 21 & $0.5 \pm 0.1$ & $83.3 \pm 20.0$ \\
$\mathrm{~N} 1$ & 10 & 37 & $0.4 \pm 0.1$ & 37 & $1.1 \pm 0.1$ & $275.0 \pm 9.1$ \\
$\mathrm{~N} 2$ & 3 & 21 & $1.1 \pm 0.3$ & 21 & $1.3 \pm 0.3$ & $118.2 \pm 23.1$ \\
\hline & $\mathrm{B}$ & carefully filled & $\begin{array}{l}\text { oxygen conc. at start } \\
\text { oxygen conc. at start } \\
\text { temperature } \\
\text { temperature }\end{array}$ & & $\begin{array}{l}\mathrm{B} 1=1.1 \mathrm{mg} / 1 \\
\mathrm{~B} 2=0.6 \mathrm{mg} / 1\end{array}$ \\
$\mathrm{~N} 1=37^{\circ} \mathrm{C}$ & $\mathrm{N} 2=21^{\circ} \mathrm{C}$ & \\
\hline
\end{tabular}

pletely reaerated. It is notable, that the paddle method induces much faster reaeration than the basket method. For example, 50 rpm paddle introduces $2.9 \mathrm{mg} / \mathrm{L}$ of oxygen into the medium within 120 minutes, whereas the $100 \mathrm{rpm}$ basket procedure results in an uptake of 2 $\mathrm{mg} / \mathrm{L}$ in the same time interval. The data also indicate that there is an uptake of oxygen even when the medium is not exposed to forced convection. In the absence of stirring, the oxygen concentration in the medium increases by $1.5 \mathrm{mg} / \mathrm{L}$ after $120 \mathrm{~min}$.. It can be hypothesized that natural convection - caused by small temperature differences in the water bath - as well as diffusion contributes to this effect.

The graph at left(Fig.2) describes the rate of reaeration of the dissolution test medium at $100 \mathrm{rpm}$. The paddle apparatus is compared with the basket at approximately the same starting concentration of oxygen. It is clearly shown that the different test conditions result in different rates of oxygen uptake. Further it is indicated that for long term dissolution tests with extended release dosage forms any efforts to deaerate the media are nullified by the dissolution test procedure itself.

The two filling methods clearly exhibit different levels of oxygen reaeration (Table 3): about $0.5 \mathrm{mg} / \mathrm{L}$ for the "careful technique" (B) and more than $1 \mathrm{mg} / \mathrm{L}$ for the "standard laboratory procedure" $(\mathrm{N})$. If the "starting" concentration of oxygen is very low (under $1 \mathrm{mg} / \mathrm{L}$ oxygen content before filling the dissolution vessels) as may be the case when deaeration and filling are performed at $37^{\circ} \mathrm{C}(\mathrm{N} 1)$, the increase in oxygen concentration during filling may be as great as $275 \%$.

For further details about the grounds for deaerating of dissolution media and the rationale for using oxygen as a "dissolution tool" see [6]. 


\section{Dissolved Oxygen....continued}

\section{Conclusions}

A fast, efficient and reproducible deaeration method, without the need for expensive helium was developed. This method consist of a combination of ultrasound and vacuum. The efficiency of deaeration was measured directly by the decrease in oxygen concentration. The advantage of direct measurement over the use of calibrator tablets for this purpose is clear: it avoids the influence of any tablet-to-tablet differences on the results.

The reported data show that the rate of reaeration is influenced by the way the deaerated medium is filled into the dissolution vessels as well as is being highly dependent on the dissolution method.

\section{References}

[1] Qureshi, S. A., McGilveray, I. J.; A Critical Assessment of the USP Dissolution Apparatus Suitability Test, Drug Dev. Ind. Pharm., 21 (8), 905-924 (1995)

[2] Lide, D. R, (Editor); CRC Handbook of Chemistry and Physics, 74 th Edition, Chapter 63, CRC Press, West Palm Beach, FLA (1993-1994)

[3] USP 23/NF 18, United States Pharmaeopeial Convention, Rockville, MD, 1792, Footnote 3 (1994)

[4] Skoug, J. W., Halstead, G. W., Theis, D. L., Freeman, J. E., Fagan, D. T., Rohrs, B. R.; Strategy for the Developement and Validation of Dissolution Test for Solid Oral Dosage Forms, Pharm.
Technol. 58-72 (1996)

[5] Clark, L.C.,U.S. Patent 2913386 (1959)

[6] Diebold, S.M. and Dressman, J.B.; Entgasung und Wiedersättigung von wäßrigen Medien für Lösungsgeschwindigkeitstests. Pbarm. Ind. 60 (4), 354-359 (1998)

\section{Correspondence}

Prof. Dr. Jennifer B. Dressman Institut für pharmazeutische Technologie

Marie-Curie-Straße 9

60439 Frankfurt a. $M$.

Tel.: 069 / 79829680

Fax: $069 / 79829694$

Apotheker Steffen M. Diebold

BruehIstraße 22

72393 Burladingen

Tel.: 07477 / 406 